\title{
Therapeutic anti-cancer activity of antibodies targeting sulfhydryl bond constrained epitopes on unglycosylated RON receptor tyrosine kinase
}

\author{
Xin Yu Koh ${ }^{1} \cdot$ Xiao Hui Koh ${ }^{1} \cdot$ Le-ann Hwang ${ }^{1} \cdot$ Fernando Jose Ferrer ${ }^{1} \cdot$ Siti Aishah Binte Rahmat ${ }^{1} \cdot$ Dilraj Lama $^{2}$. \\ David P. Lane $\mathbb{I}^{1}$
}

Received: 25 March 2019 / Revised: 13 June 2019 / Accepted: 25 June 2019 / Published online: 15 August 2019

(c) The Author(s) 2019. This article is published with open access

\begin{abstract}
Recepteur d'origine nantais (RON) receptor tyrosine kinase (RTK) and its ligand, serum macrophage-stimulating protein (MSP), are well-established oncogenic drivers for tumorigenesis and metastasis. RON is often found to be alternatively spliced resulting in various isoforms that are constitutively active. RON is therefore an attractive target for cancer therapeutics, including small molecular inhibitors and monoclonal antibodies. While small molecule inhibitors of RON may inhibit other protein kinases including the highly similar MET kinase, monoclonal antibodies targeting RON are more specific, potentially inducing fewer side effects. Although anti-RON monoclonal antibody therapies have been developed and tested in clinical trials, they were met with limited success. Cancer cells have been associated with aberrant glycosylation mechanisms. Notably for RON, the loss of N-bisected glycosylation is a direct cause for tumorigenesis and poorer prognosis in cancer patients. Particularly in gastric cancer, aberrant RON glycosylation augments RON activation. Here, we present a novel panel of monoclonal antibodies which potentially widens the specific targeting of not only the glycosylated RON, but also unglycosylated and aberrantly glycosylated RON. Our antibodies can bind strongly to deglycosylated RON from tunicamycin treated cells, recognise RON in IHC/IF and possess superior therapeutic efficacy in RON expressing xenograft tumours. Our most potent antibody in xenograft assays, is directed to the RON alpha chain and targets a sulfhydryl bond constrained epitope that appears to be cryptic in the crystal structure. This establishes the paradigm that such constrained and cryptic epitopes represent good targets for therapeutic antibodies.
\end{abstract}

\section{Introduction}

Recepteur d'origine nantais (RON) is a tyrosine kinase receptor belonging to the MET family of receptors [1]. Macrophage-stimulating protein (MSP) is the only known ligand of RON [2]. RON is structurally homologous to hepatocyte growth factor receptor (HGFR), also known as

Supplementary information The online version of this article (https:// doi.org/10.1038/s41388-019-0946-8) contains supplementary material, which is available to authorized users.

David P. Lane

dplane@p53Lab.a-star.edu.sg

$1 \quad$ P53 Laboratory, Agency for Science, Technology and Research (A*STAR), Singapore, Singapore

2 Bioinformatics Institute, Agency for Science, Technology and Research (A*STAR), Singapore, Singapore
MET. Like MET, RON is expressed as an $185 \mathrm{kDa}$ glycosylated pro-RON chain, which is subsequently processed by protease mediated cleavage into a functional $35 \mathrm{kDa}$ alpha RON chain and a $150 \mathrm{kDa}$ beta RON chain, linked by disulphide bridges [3]. The alpha chain is fully extracellular while the beta chain is made up of an extracellular SEMA domain, three IPT domains, a transmembrane domain and an intracellular tyrosine kinase domain [4].

The MSP/RON pathway was first identified to be an oncogenic driver of multiple malignancies nearly two decades ago [5]. Activation of the MSP/RON pathway leads to downstream activation of multiple signalling pathways including the PI3K/Akt pathways, resulting in regulation of important cellular processes like cell survival and proliferation, angiogenesis and transformation [3]. Aberrant RON activities in cancer are mostly caused by receptor overexpression and alternative splicing, which results in constitutively active RON isoforms [6, 7]. For example, 
short-form RON (sfRON) was reported to be involved in the pathogenesis of ovarian cancer [8].

With the rising popularity of targeted therapies over traditional chemotherapy for cancer treatment, there have been considerable efforts to also target RON in multiple malignancies for precision therapy [9]. RON can be overexpressed in pancreas, colon and breast cancers along with other primary cancers, and is reported to be a safe molecule to target [10]. RON TK-/- mice with a homozygous deletion in the RON tyrosine kinase domain are viable and appear to be phenotypically normal, with defects in their inflammatory responses [11]. Clinically, inhibition of RON using monoclonal antibodies is well tolerated by cancer patients [12]. Development of RON targeting therapeutics is currently dominated by small molecule inhibitors and monoclonal antibodies [10, 13]. Several small molecule inhibitors have shown moderate preclinical inhibition of tumour growth in mice xenograft experiments involving RON expressing cancer cell lines, in combination with other chemotherapeutic agents [14]. However, small molecule drug development efforts are focused on targeting the kinase domain of RON and are associated with crossinhibition of MET and/or other receptor tyrosine kinases [10].

In contrast, the use of monoclonal antibodies to target extracellular RON therapeutically allows for higher specificity and possibly higher affinities to the target $[10,15]$. A few groups have documented monoclonal antibodies that, as a single agent, achieve the same degree of tumour inhibition as their small molecule counterparts, with reduced off-target side effects [16]. While the development of these RON targeting monoclonal antibodies may have improved the profile of targeting RON significantly, there remains considerable interest in single RON targeting agents that can result in complete inhibition [17]. Clinical testing of the leading monoclonal antibody Narnatumab (IMC-RON8) was abandoned following a report of lack of efficacy in Phase I trials on the investigated dosing regimen. Narnatumab had a short half-life of less than 7 days leading to suboptimal drug exposures for the patients [18].

For the past 20 years, most studies on aberrant RON activation have been focused on alternative RON splicing and its isoforms [19, 20]. More recently, cumulative evidence demonstrated aberrant glycosylation of proteins in cells can lead to tumorigenesis and cancer progression-a novel emerging hallmark of cancer [21]. Glycosylation is a post-translation modification that occurs when sugar moieties are covalently added to immature proteins in the endoplasmic reticulum and Golgi apparatus before secretion [22]. This modification allows for greater proteomic diversity, and is a vital regulator of many biological processes in cells [23].
Protein glycosylation can be classified into different groups: $N$-linked glycans, $O$-linked glycans, $C$-linked glycans and phosphoglycans [24]. Particularly, for transmembrane receptor tyrosine kinases, including IGFR, VEGFR and EGFR, $N$-linked glycosylation is a critical step for their maturation and function [25]. Glycotransferases recognise specific NXS/T amino acid sequences within the immature tyrosine kinase proteins and initiate a transfer of sugar moieties to the asparagine residue [26]. The sugar molecule is then subjected to further modifications in the ER and Golgi before protein secretion into the cell surface as a properly folded mature protein [27]. Glycosylation of transmembrane tyrosine kinases affect the proteins' folding, stability and plasma membrane retention time [28]. Aberrantly glycosylated RTKs tend to have a longer plasma membrane retention time leading to increased kinase activity and downstream signalling driving cellular oncogenesis, as reported in IGFR and HER2 [29].

More recently, RON activity in cancer cells is reported to be regulated by glycosylation modifications in gastric cancer patients [30]. Aberrantly glycosylated RON molecules that are constitutively active lead to increased retention times and an increase in tumorigenic activities.

Current RON targeting monoclonal antibodies are focused on inhibiting properly folded and glycosylated proteins. However, the antibodies might elude the targeting of many aberrantly glycosylated RON and unglycosylated misfolded RON molecules present in cancer cells. In this report, we describe a panel of monoclonal antibodies targeting unglycosylated RON. Our antibodies bind strongly to aberrantly glycosylated RON from tunicamycin treated cells, recognise RON in IHC/IF and have superior therapeutic efficacies in RON xenograft tumours. Detailed examination of the epitope recognised by the most potent antibody in xenograft assays established that it recognised a cryptic sulfhydryl constrained epitope in the protein that is exposed when cells are fixed with both paraformaldehyde and methanol-acetone. The epitope's expression is also dramatically increased when cells are treated with tunicamycin, a potent inhibitor of glycosylation. While the antibody appears to be inactive in cell-based assays of tumour cell growth, it shows remarkable potency in xenograft studies. The implication of this work is that the environment of actively growing tumours may create an opportunity for antibodies to recognise epitopes that are normally only exposed under conditions where protein folding is compromised. As such cryptic epitopes would not be expected to be displayed on normal tissues, this class of antibodies may show superior tumour specific activity. Studies of the EGFR antibody 806 show very similar effect as the epitope recognised by that antibody is also cryptic but exposed on mutant forms of the receptor [31]. 


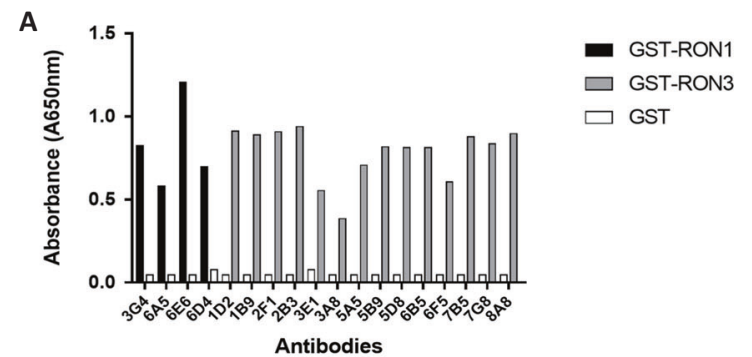

B
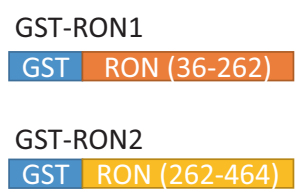

GST-RON3

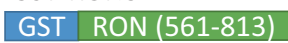

D

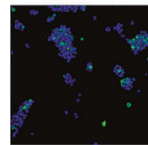

$2 \mathrm{~B} 3$

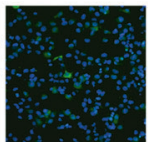

3E1
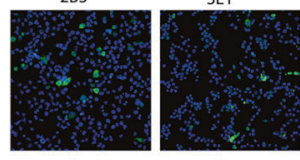

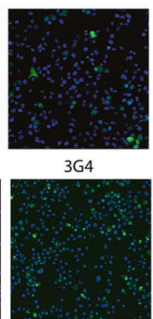

6D4
C $\mathrm{kDa} \frac{3 \mathrm{G} 4}{+-} \frac{6 \mathrm{E} 6}{+- \text { Transfection }}$

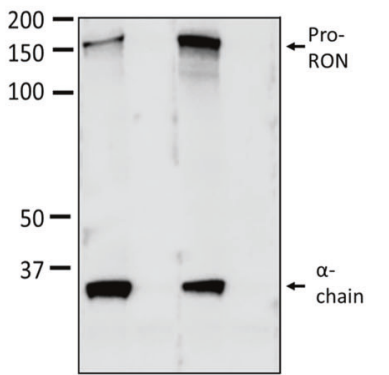

Fig. 1 RON antibodies panel screened by ELISA, western blotting and cell staining. a 18 hybridoma clones chosen from 2112 hybridomas were screened against the RON1 and RON3 protein antigens in ELISA. GST was used as a negative control antigen. Absorbance was measured at $650 \mathrm{~nm}$. b Three constructs were constructed as RON1, RON2 and RON3 antigens used for immunization in mice. The RON proteins were fused to GST tag at the $\mathrm{N}$ terminus and expressed recombinantly in $E$. coli cells. c Western blot analysis of two clones $3 \mathrm{G} 4$ and 6E6 on $293 \mathrm{~T}$ cell lysate transfected with full length $R O N$ plasmid ran on 4-12\% gradient gel. Lanes 1 and $3(+)$ indicates cells transfected with full-length $R O N$ plasmid and lanes 2 and 4: (-) indicates untransfected cells. 3G4 and 6E6 bind to an epitope on alpha chain of RON, represented by pro-RON $(180 \mathrm{kDa})$ and alpha-RON bands $(35 \mathrm{kDa})$. d Immunofluorescence staining of $\mathrm{H} 1299$ cells transfected with full-length $R O N$ plasmid with a c-Myc tag using supernatants from hybridoma clones. Cells were stained with DAPI (blue) for nuclei visualisation and antibodies (green) using anti-mouse Ig secondary antibody conjugated with Alexa Fluor 488. Eight hybridoma clones were chosen for further development. Anti-c-Myc antibody 9E10 (Santa Cruz Biotechnology) was used as a positive control to visualize RON-transfected staining

\section{Results}

\section{Screening for panel of antibodies targeting RON}

In this study, a total of 2112 hybridoma clones were screened against RON antigens in ELISA and high throughput immunofluorescence screening. From our ELISA screening data (Fig. 1a), 18 hybridoma clones were identified as positive binders for RON1 and RON3 antigens that were not cross reactive to the negative antigen GST. From the ELISA screenings, there were no specific clones targeting RON2 antigen.

The panel of RON targeting antibodies were obtained by immunizing three groups of mice with different extracellular RON domain antigens. Three antigens were used for the immunization. These comprised RON1 (alpha chain residues 25-262), RON2 (beta chain sema domain residues 262-464) and RON3 (IPT domain residues 561-813) (Fig. 1b). Following an optimized immunization schedule for antibody production, sera were collected from immunized mice after four boosts and tested for activities against corresponding RON antigens in ELISA. Spleens from mice showing the highest antibody titres were harvested for fusion with SP2/0 myeloma cells for monoclonal antibody production.

The ELISA positive clones were screened for RON binding by western blotting and cell staining assays. Two hybridoma clones 3G4 and 6E6, recognized two bands corresponding to pro-RON $(180 \mathrm{kDa})$ and alpha chain of RON (35 kDa), respectively, in RON transfected H1299 cells by western blotting (Fig. 1c). Eight clones-2B3, 3G4, 3E1, 5A5, 5B9, 6E6, 6D4 and 7G8 were identified to strongly stain RON transfected H1299 cells in immunofluorescence staining (Fig. 1d, Table 1). In summary, eight antibodies that recognize transfected RON protein in immunofluorescence staining of which two are compatible with western blotting, were discovered from our antibody screening. Data from antibody screening and characterization assays are summarized in Table 1 .

\section{Testing the antibodies on cancer cell lines and tissues}

To evaluate antibody targeting of RON in cancer cell lines and tissues, a series of tests on cancer lines expressing RON were carried out. Antigen retrieval of RON was optimal at pH 6 on HT29 xenograft tissue sections stained with RON antibodies (Fig. 2a). 3G4, 6E6, 5B9, 6D4 and 7G8 showed RON staining mainly in the cytoplasm with some in the nucleus. 2B3, 3E1 and 5A5 showed no staining on HT29 sections as HT29 cells express RON $\Delta 160$, an isoform of RON with an in-frame deletion [10], where the antibodies bind.

Immunoblotting was also carried out across a panel of RON expressing cell lines including colorectal cancer lines HT29, HCT116 and WiDr; breast cancer line T47D and gastric cancer line MKN45. Rat glioma cells C6 and nonsmall cell lung cancer H1299 cells were used as negative controls. 3G4 and 6E6 recognized two bands in the positive 
Table 1 Summary of RON antibodies properties and characteristics

\begin{tabular}{llllllll}
\hline Antibody clone & Epitope & Isotype & ELISA & $\begin{array}{l}\text { Western } \\
\text { blotting }\end{array}$ & $\begin{array}{l}\text { Cell } \\
\text { staining }\end{array}$ & Internalisation & Xenograft \\
\hline 2B3 & IPT1 & IgG1 & ++ & - & ++ & - & NT \\
$3 E 1$ & IPT1 & IgG1 & + & - & + & - & NT \\
$3 G 4$ & Alpha Chain & IgG1 & ++ & ++ & ++ & - & NT \\
5 A5 & IPT1 & IgG1 & +++ & - & ++ & ++ & NT \\
$5 B 9$ & IPT3 & IgG1 & +++ & - & ++ & ++ & NT \\
6 D4 & IPT3 & IgG1 & +++ & - & +++ & +++ & - \\
6 E6 & Alpha Chain & Ig2a & +++ & ++ & ++ & - & +++ \\
$7 G 8$ & IPT3 & IgG1 & +++ & - & +++ & +++ & ++ \\
\hline
\end{tabular}

lysates, one corresponding to $180 \mathrm{kDa}$ pro-RON and a second lower alpha-RON band at $35 \mathrm{kDa}$ (Fig. 2b). There was no cross reactivity to the negative lysates. The RON protein has many different isoforms [6] but the majority of these retain the alpha chain sequences recognised by our antibodies. This may account for variations in the size of RON bands detected in different cell lines.

Immunofluorescence staining was performed on paraformaldehyde fixed HCT116 and T47 cells. All RON antibodies gave a similar cytoplasmic staining pattern to C-20 (Santa Cruz Biotechnology), a commercial rabbit polyclonal antibody that targets the $\mathrm{C}$ terminus of beta-RON (Fig. 2c).

\section{Fixation methods affect antibody staining of RON epitopes}

To investigate if the antibodies can stain cells for flow cytometry analyses, RAJI cells were treated with different fixation methods, unfixed, PFA fixed, or acetone methanol fixed, before staining with RON antibodies. The results indicate the RON epitopes to be differently exposed for staining with our RON antibodies when they are treated with different fixation methods (Fig. 3). For the RAJI cells that are stained live without fixation, 6D4 and 7G8 staining showed a larger population of stained cells out of the panel of RON antibodies. In contrast, cells that are paraformaldehyde fixed showed a different antibody staining profile. Some antibodies like 3G4, 6E6, 2B3 and 5A5 showed markedly increased staining of RAJI cells after paraformaldehyde fixation to a level similar to 6D4 and 7G8 staining. When RAJI cells are fixed in acetone methanol, all RON antibodies were able to stain RON epitopes to a similar extent. This implies that the antigenic structure of RON presented at the cell surface in highly constrained compared with epitopes expressed on intracellular forms of the protein.

\section{RON antibodies strongly stain unglycosylated RON}

In the study, our panel of RON antibodies were raised against bacterially produced unglycosylated RON antigens.
As such, it was reasoned that our RON antibodies will show increased staining on unglycosylated RON antigens. To study this HCT116 cells were treated with tunicamycin, a glycosylation inhibitor, for $48 \mathrm{~h}$ in complete media. Following tunicamycin treatment, cells were paraformaldehyde fixed and stained with RON antibodies overnight. Consistent with our predictions, all of our RON antibodies showed a marked increase in RON staining of the treated HCT116 cells (+) in comparison to the untreated HCT116 cells (-) (Fig. 4).

\section{D4 and 7G8 blocks MSP mediated downstream signalling of RON receptor}

We studied our RON antibodies' effects on MSP stimulation downstream of the RON signalling pathway. We chose to study the two antibodies that give the strongest staining of unfixed cells in flow cytometry namely 6D4 and 7G8. In our study, we found the breast cancer cell line T47D to be sensitive to MSP stimulation as it showed a marked increase in ERK phosphorylation levels after MSP treatment. RON antibodies $6 \mathrm{D} 4$ and $7 \mathrm{G} 8$ were incubated with T47D cells for $48 \mathrm{~h}$ in the blocking step before a 30-min MSP stimulation of the RON receptor. As shown in Supplementary Figure 1, in the absence of MSP, the levels of phosphorylated ERK in the presence of the 6D4 or 7G8 are relatively constant. When MSP is added, MSP increases the phosphorylation levels of ERK. This effect is abrogated in the presence of 6D4 and 7G8 antibodies, showing that RON receptor is blocked by the antibodies, such that the downstream signalling through the ERK/MAPK pathway is reduced.

\section{D4 and 7G8 inhibit cancer cell proliferation; 7G8 inhibits in vitro wound healing}

To determine the effect of our antibodies on the proliferation of RON expressing HT29 cells, inhibition assays were carried out using the IncuCyte Live Cell Analysis System (Essen BioScience). Following $72 \mathrm{~h}$ of $\mathrm{mAbs}$ incubation, HT29 cells were continuously monitored for 4 more days. Cell proliferation data from IncuCyte showed that 6D4 
A

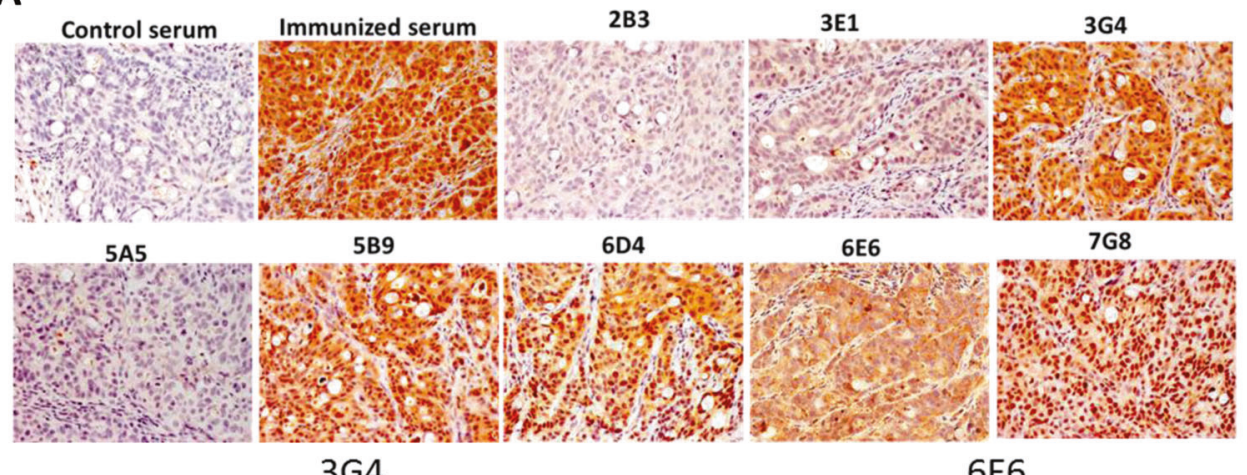

B
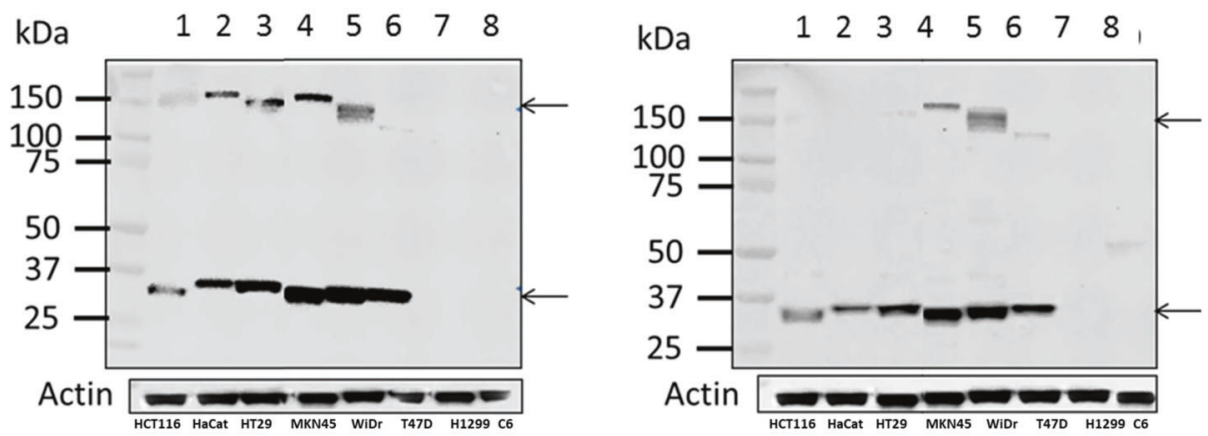

C
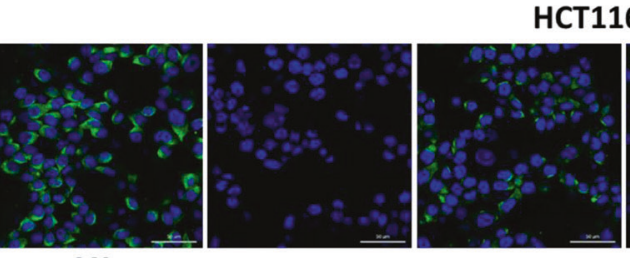

2B3
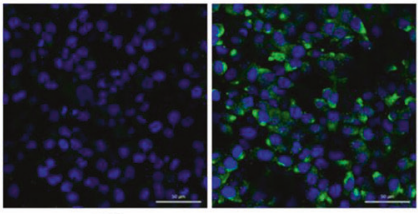

3E1
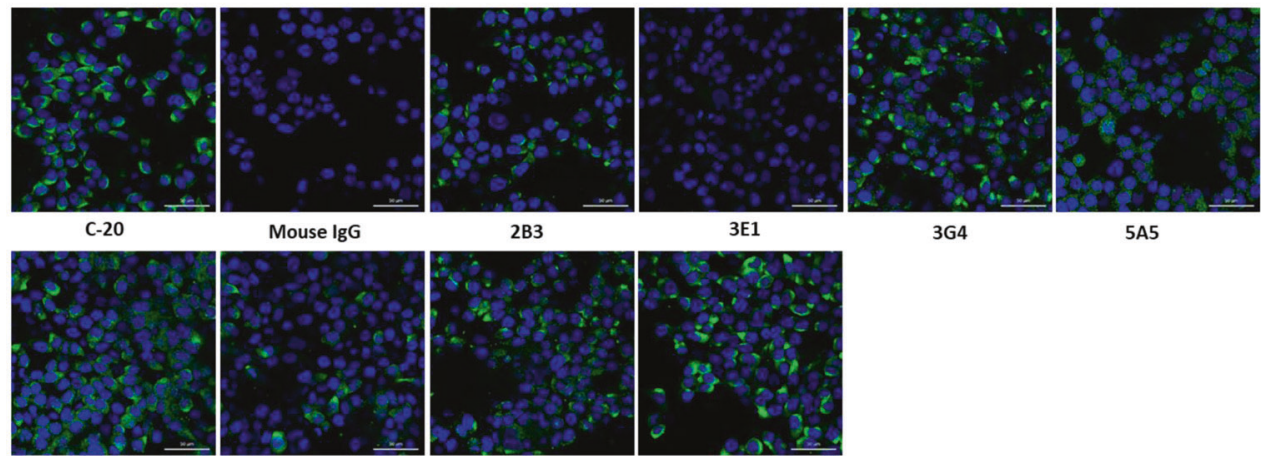

Mouse IgG
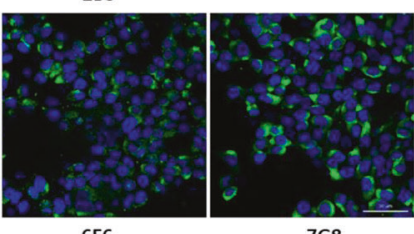

$5 A 5$

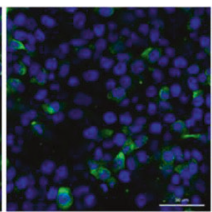

$6 \mathrm{D} 4$

T47D
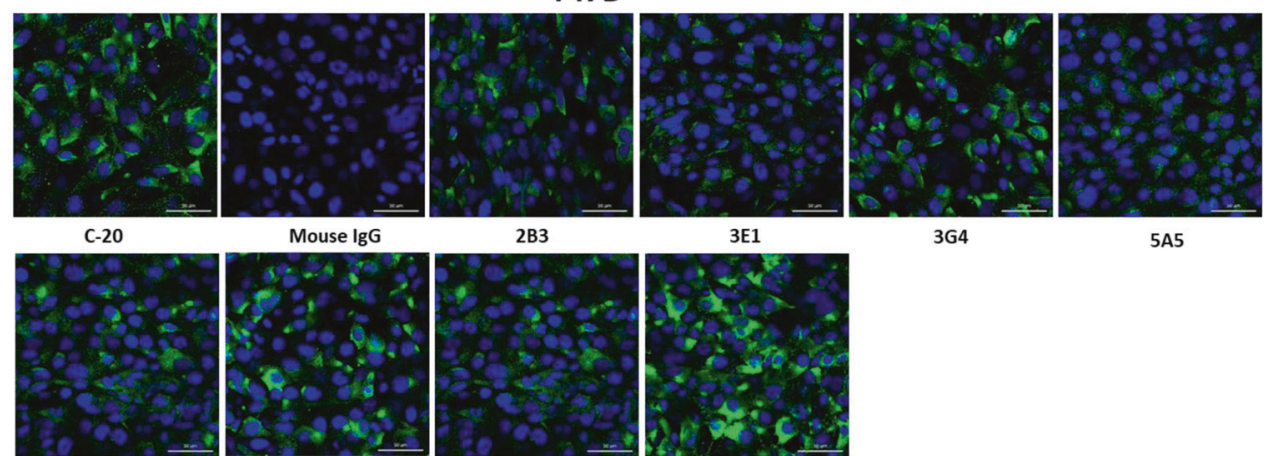

Mouse IgG

3E1

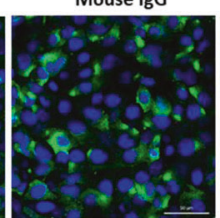

6D4
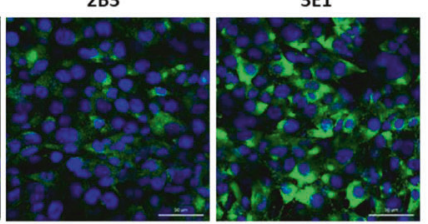

$5 \mathrm{~A} 5$

inhibited the growth of HT29 cells in a dose dependent manner. The growth of HT29 was inhibited in vitro by $\sim 35 \%$ at $6 \mathrm{D} 4$ concentrations of 12.5 and $6.25 \mu \mathrm{g} / \mathrm{ml}$
(Supplementary Figure 2). At $3.13 \mu \mathrm{g} / \mathrm{ml}$, cells treated with 6D4 showed a decreased inhibition of cells growth to $15 \%$. This effect was ameliorated when 6D4 concentration was 
Fig. 2 RON antibodies stain RON in immunohistochemistry and recognizes endogenous RON in different cancer lines. a Immunohistochemistry staining of RON on HT29 xenograft tumours by hybridoma supernatants. Tumours from HT29 xenograft mice were harvested and embedded in paraffin blocks for immunohistochemistry staining. Analyses showed staining of mainly the cytoplasm and some nuclei. b Western blot analysis of six cancer lines expressing endogenous RON including HCT116, HaCaT, HT29, MKN45, WiDr and T47D was performed using 3G4 and 6E6. H1299 and C6 lines were used as non RON expressing negative controls. Pro-RON and alphaRON bands were detected in all positive cell lines. $\mathbf{c}$ Confocal images showing immunofluorescence staining of HCT116 cells and T47D cells using RON antibodies. Cells were stained with DAPI (blue) for nuclei visualisation and antibodies (green) using anti-mouse/rabbit Ig secondary antibody conjugated with Alexa Fluor 488. Commercial anti-RON rabbit polyclonal antibody $\mathrm{C}-20$ was used as a positive control to visualise RON staining. Polyclonal mouse $\mathrm{IgG}$ was used as a negative control. Scale bar: $50 \mu \mathrm{m}$

halved to $1.56 \mu \mathrm{g} / \mathrm{ml}$. $7 \mathrm{G} 8$ treatment caused a consistent inhibition of HT29 cell growth by around 50\% at concentrations of $12.5-1.56 \mu \mathrm{g} / \mathrm{ml}$ (Supplementary Figure 2). No significant difference in cell proliferation was observed following 6E6 treatment, consistent with its poor binding to RON at the cell surface detected by flow cytometry of unfixed cells, even though 6E6 was shown to be an antialpha chain antibody in western blot.

RON antibodies were next tested to see if they could block MSP mediated cell proliferation in vitro (Supplementary Figure 2B). These were incubated at $1.56 \mu \mathrm{g} / \mathrm{ml}$ with serum starved cells for an hour before addition of $10 \mathrm{~nm}$ MSP into the media. Cell proliferation activity monitored over $90 \mathrm{~h}$ showed that both 6D4 and 7G8 antibodies were able to inhibit the effects of MSP mediated cell proliferation.

RON signalling can promote increases cell migration and metastasis. Analysis of the effects of 6D4 and 7G8 treatment on cell migration was carried out with a scratch wound assay. At $10 \mu \mathrm{g} / \mathrm{ml}$, treatment of HT29 cells significantly inhibited the healing of the wound by $23 \%$ (Supplementary Figure 2C). 6D4, however, failed to cause any inhibition in the closure of the wound at the same concentration. As anticipated antibodies that failed to strongly recognise RON at the cell surface such as the antibody 6E6 caused no growth inhibition and could not block cell migration.

\section{RON antibodies inhibit tumour growth in xenografts}

The therapeutic effect of multiple doses $(25 \mathrm{mg} / \mathrm{kg})$ of mAbs 6D4, 6E6 or 7G8 on human cell line HT29-luc derived tumours was investigated. Dosing was performed as shown in Fig. 5a. The last antibody treatment was performed on Day 28 after which tumours were allowed to grow for another 2 weeks to monitor their progress after the end of treatment. Previous experiments carried out to test the toxicities of the antibodies by measuring weight loss of the mice after multiple injections showed that there was no significant weight loss with antibody treatment.

At the end of the experiment, luciferase imaging data obtained at Day 40 of the remaining mice is shown in Fig. 5b. Nude mice treated with 6E6 antibodies showed an inhibition of $79.8 \%$ tumour size compared with mouse IgG treated control, $7 \mathrm{G} 8$ antibodies treatment gave an inhibition of $61.0 \%$ tumour size, and mice treated with 6D4 showed a slight inhibition of $11.9 \%$ tumour size compared with mouse IgG control (Fig. 5b). Tumour mass was measured at sacrifice on a digital weighing balance (Fig. 5c). Tumours from $6 \mathrm{E} 6$ treated mice were significantly smaller than that of the mouse $\operatorname{IgG}$ treated mice $(p<0.05)$. Tumours from $7 \mathrm{G} 8$ treated mice appeared smaller than mouse IgG treated mice but there was no significant difference for 6D4 treated mice in comparison with mouse IgG treated mice. Antibodies 6E6 and 7G8 both showed strong therapeutic abilities to inhibit HT29 tumour xenograft growth in nude mice.

Tumour measurement data over the 40 days are shown in Fig. 5d, e. Antibodies 6E6 and 7G8 showed significant $(p<$ 0.05 ) inhibition of tumour growth up to Day 28, and even after the cessation of antibody treatment, tumour growth remained relatively slower in comparison with mouse $\mathrm{IgG}$ treated tumours. 6D4 antibody treated tumours did not show significant inhibition in comparison to mouse $\mathrm{IgG}$ treated tumours. What is remarkable however is the superior efficacy of the antibody 6E6 in xenografts when it does not appear to bind to RON presented at the cell surface in tissue culture analyses.

\section{RON antibody treated tumours show a marked increase in apoptotic markers and a decrease in proliferative marker expression}

Histologic examination of the centre of the tumours on Day 40 after mice sacrifice revealed large areas of apoptotic cells for the 6D4, 6E6 and 7G8 antibody treated tumours as seen from cleaved caspase 3 marker staining (Fig. 5). The apoptotic area for control mouse IgG treated tumour was limited to a smaller area. The tumours treated with $6 \mathrm{D} 4$, 6E6 and 7G8 antibodies showed marked decrease in their expression of proliferation markers (Ki67) compared with mouse IgG treated tumours (Fig. 5f).

\section{Mapping of the $6 \mathrm{E} 6$ epitope localises it to a sulfhydryl constrained cryptic loop in the alpha chain structure}

The efficacy of 6E6 in xenograft assays is in sharp contrast to its lack of reactivity with RON in the cell-based assays. We therefore mapped the binding site of the antibody in greater detail using a pepscan. Two peptides, numbers 30 and 31 , were reactive with the antibody, defining the epitope to the sequence GSSLQ being the common five amino 

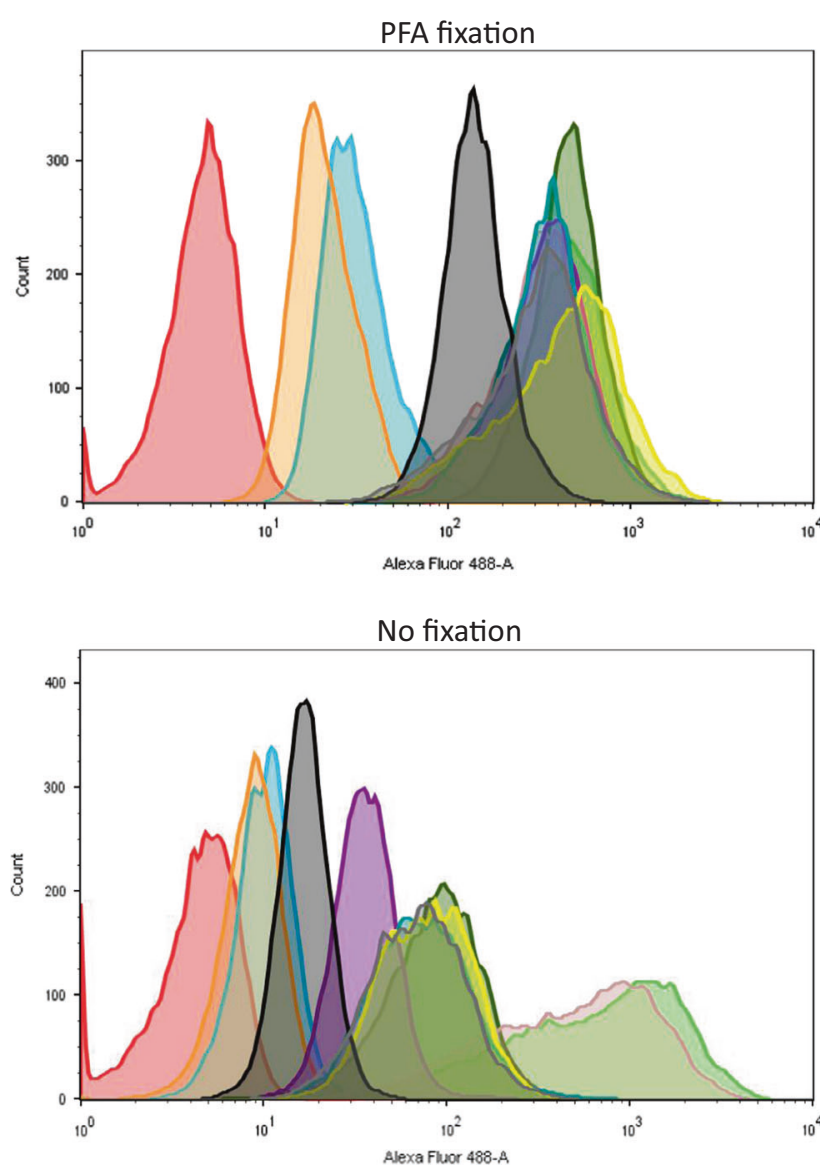

Fig. 3 Flow cytometry analysis of RON antibodies stained RAJI cells under different fixation. RAJI cells were subjected to different treatments-untreated (lower left), $4 \%$ paraformaldehyde fixation (top left) and acetone methanol fixation (top right) for $20 \mathrm{~min}$ before

acids shared between the two peptides (Fig. 6a). Analysis of the location of this peptide on the three dimensional structure of the RON alpha chain showed that the epitope was contained within a small sulfhydryl loop that is cryptic and not available at the surface of the protein (Fig. 6b, c). To further investigate this observation, we took two approaches. In the first, we used molecular dynamic simulations to ask if the SLQ epitope could ever be extruded from the surface of the alpha chain into a position where it could be bound by an antibody. As shown in Fig. 6c, representative structure from molecular dynamic simulation show that epitope could be extruded and we can hypothesize that the alteration in stability of the RON alpha domain resulting from treatment with tunicamycin or exposure to fixatives is enough to promote this dynamic alteration. Secondly, we decided to take a biochemical approach to investigate the importance of the sulfhydryl bond in the formation of the epitope recognised by $6 \mathrm{E} 6$. We used three variant peptides in surface plasmon resonance (SPR), which [1] RON-2-Ser the cysteine residues were substituted by serine, in [2] RON-2-Acm the cysteines were blocked by

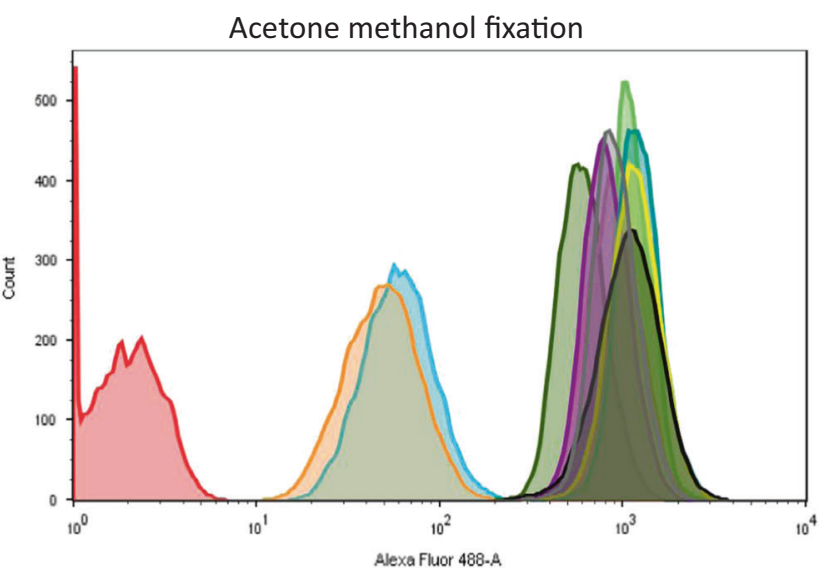

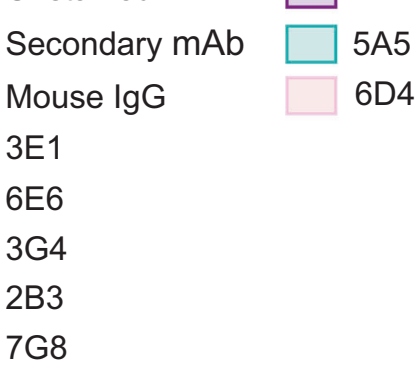

staining with RON antibodies. Cells were stained with anti-mouse secondary antibodies conjugated to Alexa Fluor 488. Mouse IgG was used as a negative control. RON staining varies differently with different fixation methods

acetamidomethyl group and in [3] RON-2-Trt in which the sulfhydryl groups (thiols) are oxidized as a disulfide bridge (Fig. 6d). The results demonstrated clearly the importance of the constrain induced by sulfhydryl bond in creating the 6E6 epitope as the SPR measurements showed much tighter binding $(5.2 \mathrm{nM})$ to the RON-2-Trt peptide than to the other two control peptides.

\section{Discussion}

\section{A novel panel of RON antibodies for diagnosis and therapy}

RON has a well elucidated role in oncogenesis, including cell proliferation and survival, cell metastasis and angiogenesis, and cell migration. This makes RON an attractive marker to target for cancer therapy. There have been various efforts to target RON for therapy using small molecule drugs and monoclonal antibodies [32]. Many RON targeting small molecule inhibitors target the kinase domains of 
Fig. 4 RON antibodies stained strongly for deglycosylated RON in colorectal cancer line HCT116. Confocal images showing HCT116 cells were treated with $\mathrm{N}$-linked deglycosylation inhibitor tunicamycin for $24 \mathrm{~h}$ before fixation with $4 \%$ paraformaldehyde for $20 \mathrm{~min}$. Cells that were untreated $(-)$ and tunicamycin treated $(+)$ were stained with RON antibodies before staining with DAPI (blue) for nuclei visualisation and antibodies (green) using anti-mouse/rabbit Ig secondary antibody conjugated with Alexa Fluor 488. RON antibodies showed significantly stronger staining of degycosylated RON as can be seen in cells treated with tunicamycin. Scale bar: $25 \mu \mathrm{m}$

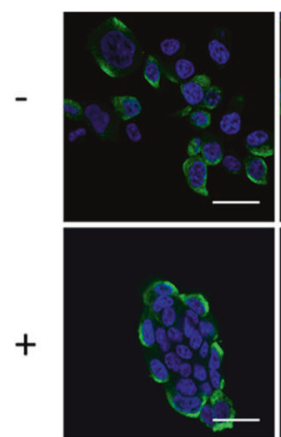

2B3

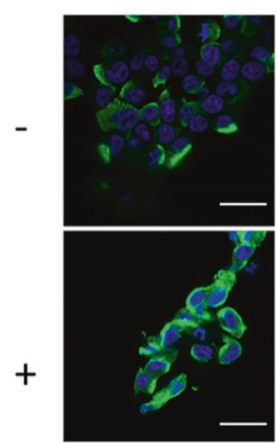

$6 \mathrm{D} 4$
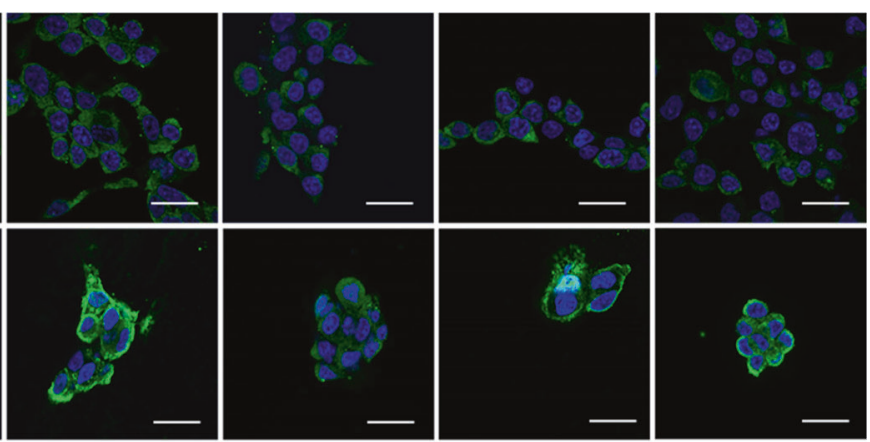

$3 \mathrm{E} 1$

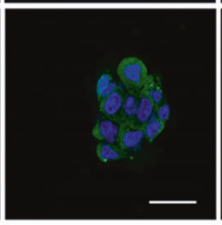

$3 G 4$

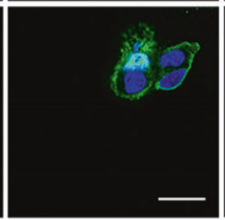

$5 \mathrm{A5}$
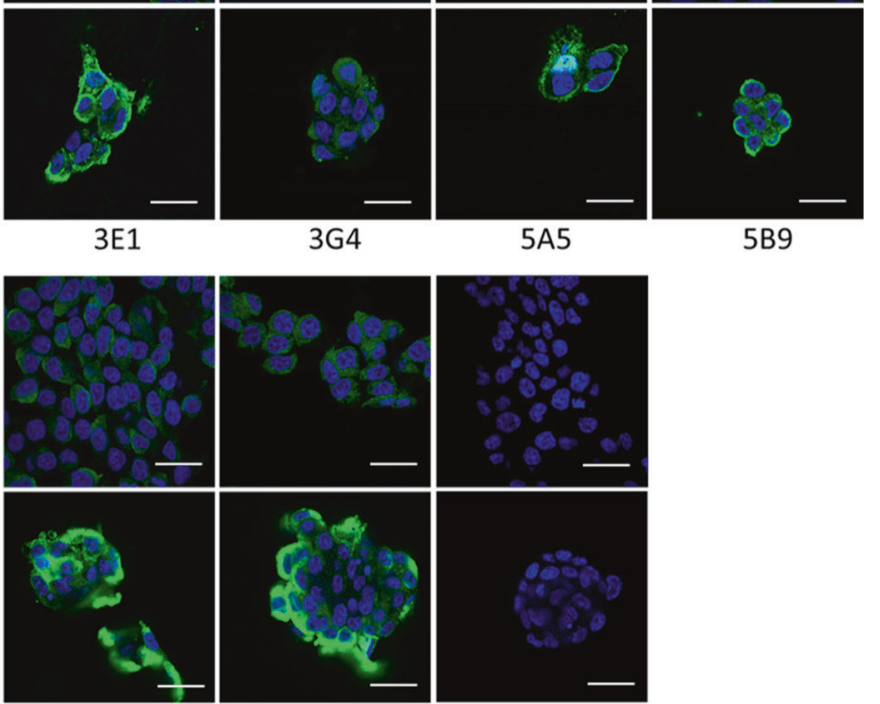

6E6

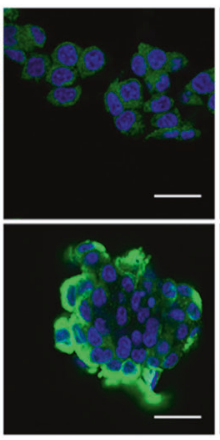

$7 G 8$

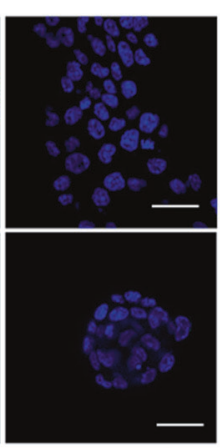

Mouse IgG
RON, which has high similarity to c-MET, conferring the drug dual specificity to both RON and c-MET, and probably other tyrosine kinases. This poses a problem as the cross reactivities of the drug can potentially bring side effects for the patient. In comparison, RON targeting monoclonal antibodies are specific and cause less off target side effects [33]. Several monoclonal antibodies have been developed by different groups and a few advanced to clinical development. However, recently, the fully human RON targeting antibody Narnatumab, reported a lack of efficacy in its phase I clinical trial study due to poor pharmacokinetics properties even though the antibody was well tolerated [18]. To date, there is still an unmet need for a RON targeting therapeutic antibody.

In our study, we present a novel panel of antibodies that can be used as diagnostics and therapeutics, but in addition, can be useful as research tools for RON studies. The antibodies can be used in multiple applications including immunohistochemistry, western blotting, ELISA, flow cytometry and immunofluorescence, in both transfected cells and cells expressing endogenous RON. In particular, the ability of our therapeutic antibodies to detect RON by immunohistochemistry is crucial as it may be an accurate predictor of therapeutic efficacy based on analysis of patient tumour biopsy samples and selection of appropriate antibodies.

We initially selected 6D4 and 7G8 antibodies for functional studies because of their abilities to detect high level of RON expression on the surface of live cells as judged by flow cytometry. Our in vitro experiments showed that 6D4 and 7G8 significantly inhibited HT29 cell proliferation and blocked MSP mediated phosphorylation of the downstream ERK marker in T47D cells. 7G8 was also effective in inhibiting cell migration in HT29 cells while 6D4 was not, probably because $6 \mathrm{D} 4$ has a lower affinity and required a higher concentration to show inhibition. These mechanisms for RON receptor are very similar to that reported by previous RON antibodies and have been well studied.

When our antibodies 6E6, 6D4 and 7G8 were tested in vivo in preclinical xenograft mouse models, 6E6 and 7G8 showed tumour inhibiting activities (Fig. 5b-e). The tumours from $6 \mathrm{E} 6$ and $7 \mathrm{G} 8$ treated mice also significantly weighed less than the tumours from control group. In our preliminary search for a suitable antibody dose, the maximum tolerated dose was not reached as the mice did not display toxicity signs like weight loss and distress even at $40 \mathrm{mg} / \mathrm{kg}$ doses. There were also no visible signs of toxicity even though $6 \mathrm{E} 6$ and 7G8 were cross reactive to mouse RON. To maximise the efficacy of our antibody drug, we decided to choose a relatively higher dose of $25 \mathrm{mg} / \mathrm{kg}$, below the $40 \mathrm{mg} /$ $\mathrm{kg}$ that were found to be safe in prior dose elevation studies.

Apoptosis plays an important role in tumour regression, and it presents an obvious target for our RON antibody therapeutic intervention. Histological analyses of the treated tumours showed that antibody treatment by $6 \mathrm{E} 6,7 \mathrm{G} 8$ and even 6D4 induced large areas of apoptotic tumour cell deaths confirmed by caspase staining (Fig. 5f). Tumour cell proliferation indicated by the expression of Ki67 marker was also reduced in the 6E6, 7G8 and 6D4 antibody treated 
A

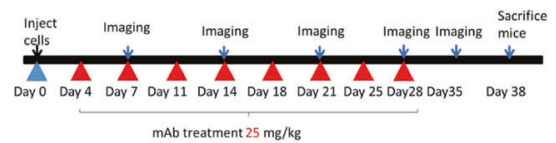

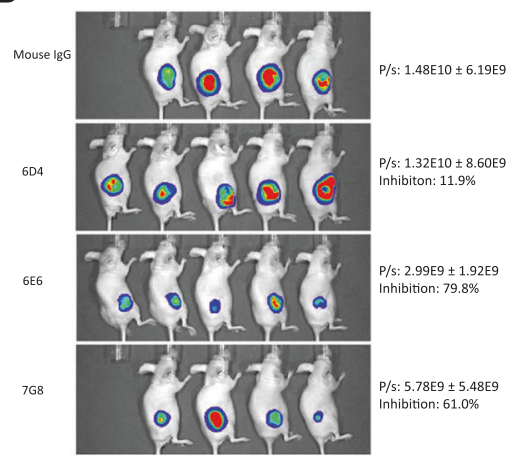

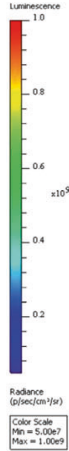

C

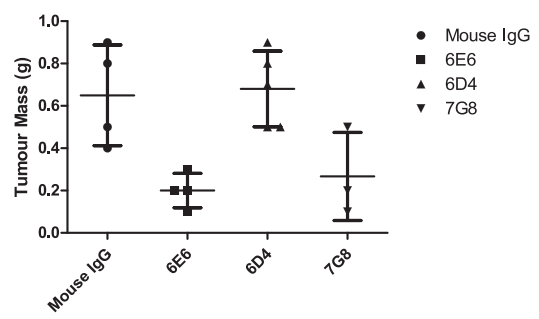

D
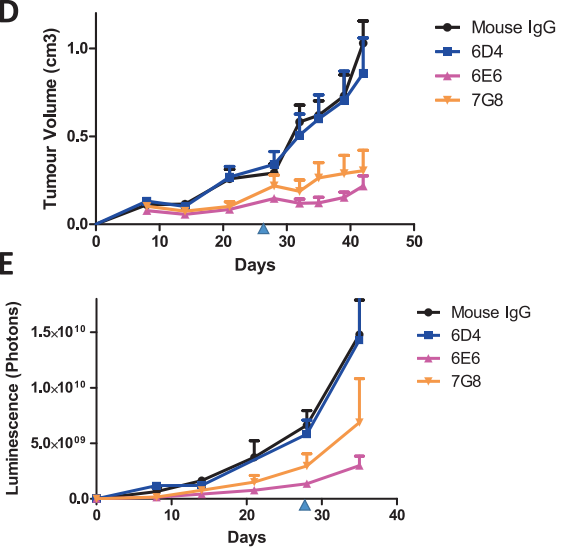

Fig. 5 RON antibodies inhibit tumour growth in HT29 xenograft mice model. a Timeline of HT 29 xenograft experiment. Animals were randomized into four groups $(n=5)$. Each red arrow head represents an intravenous antibody dose at $25 \mathrm{mg} / \mathrm{kg}$. One million HT-29luciferase cells were subcutaneously implanted in the right flank. Antibody treatment started 3 days after implantation of tumour. Blue downward arrow indicates that luciferase imaging was done. All remaining live mice were euthanized on Day 40 . b Inhibitory effect of 6E6, 6D4 and 7G8 on HT-29-luciferase mediated tumor xenografts was determined by measurement of luciferase activities using IVIS Spectrum In Vivo Imaging System (Perkin Elmer). Data are presented as means $(n=5) \pm$ S.D. using the colour scale shown. Imaging data shown was taken on Day 38 before the sacrifice of the mice. Percentage inhibition of the treatment group was calculated as a percentage of the control group. c Tumour mass measured at the end of the experiment on Day 40 on a digital weighing scale. Data are presented as means \pm S.D. d Tumour volumes measured over the 40-day period using Traceable Digital Calipers (Fischer Scientific). Tumour volumes were calculated based on the formula: Volume $=(\mathrm{LXWXH}) / 2$. Data are presented as means \pm S.D. Blue triangle denotes end of antibody treatment. e Tumour volume of xenograft tumours measured over the 40-day period based on luciferase activities of implanted HT-29 luciferase cells. Data were collected on IVIS Spectrum In Vivo Imaging System (Perkin Elmer) and presented as means \pm S.D. Blue triangle denotes end of antibody treatment. $\mathbf{f}$ RON antibodies or control antibody treated tumour tissues were harvested (from (e)) and fixed in $10 \%$ non-buffered formalin before embedding in paraffin blocks for histology analysis. Representative Ki67 (left panel) at $\times 20$, Ki67 (middle panel) at $\times 40$ and cleaved caspase 1 (right panel) at $\times 20$ stained images are shown. $\times 20$ images were shown for a wider field of view. Graph below shows Ki67 or cleaved caspase 1 staining comparison between antibodies treated tumours. Positive fraction was calculated by quantifying total area of positive DAB staining over total nuclear staining by haematoxylin using Image $\mathbf{J}$ 


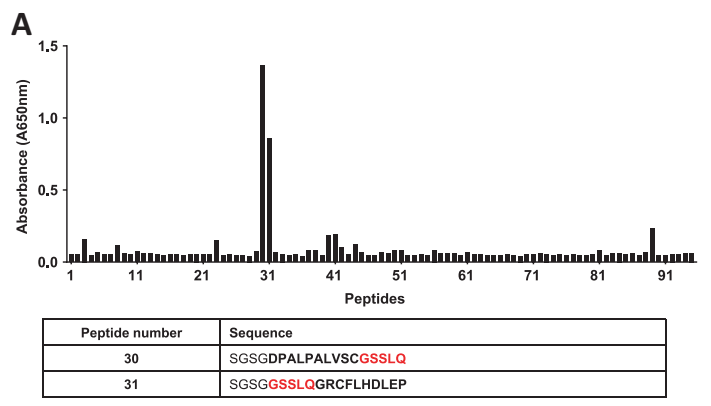

B

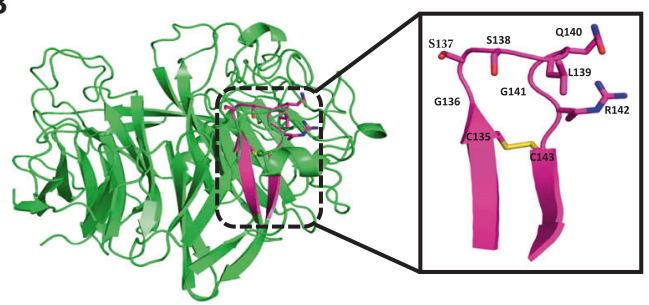

C

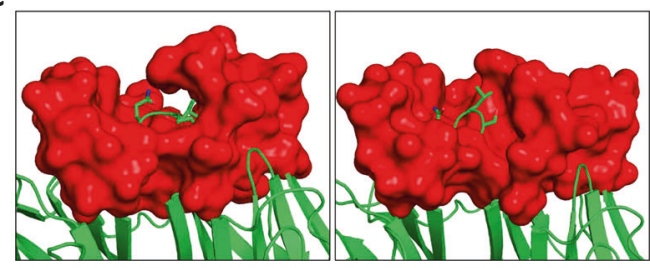

D
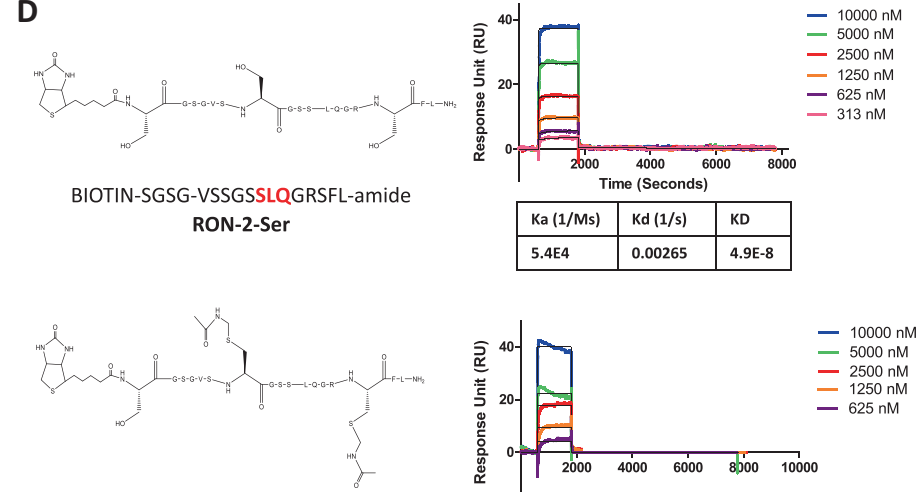

BIOTIN-SGSG-VSC(Acm)GSSLQGRC(Acm)FL-amide RON-2-Acm
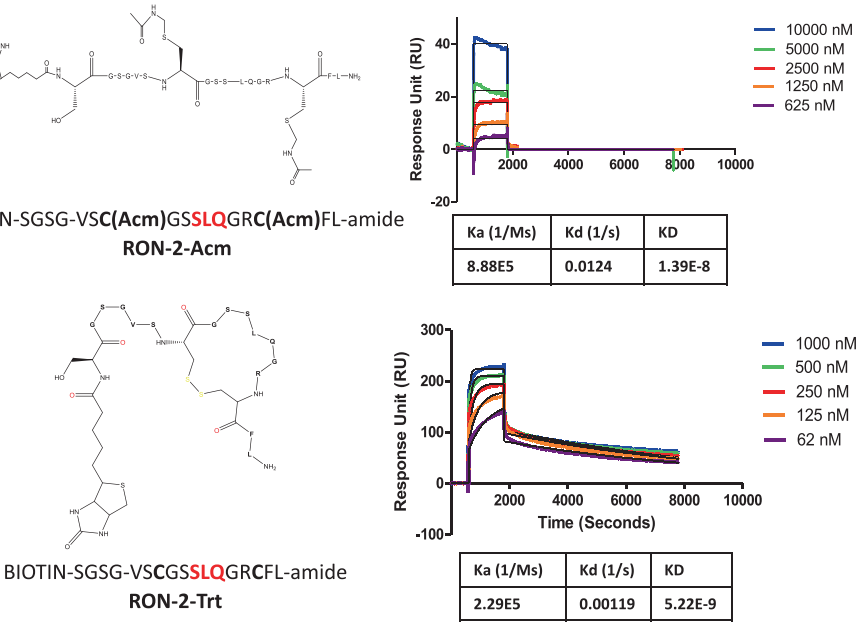

coloured in red. $\mathbf{d}$ Representative surface plasmon resonance data. SPR data showing chemically synthesized peptides binding to the immobilized 6E6 antibody. Structures of the different synthetic peptides surrounding the -SLQ epitopes are shown on the left. Three different peptides-linear RON-2-Ser (top left), linear RON-2-Acm (middle left) and cyclic RON-2-Trt (bottom left) were tested with 6E6. Corresponding binding curves are showed on the right. The legend shows the concentration of peptides in $\mathrm{nM}$; the calculated fit is shown as a black line. Binding affinities of the experiment are listed in the table below the graphs. The graphs show representative data chosen from at least three separate kinetics measurements for each of the synthetic peptides

glycoproteins with eight predicted N-glycosylation sites, four in the SEMA domain (Asn66, Asn419, Asn458 and Asn488) and one on each of the other domains $[35,36]$. Glycosylation of receptor kinase proteins regulates their retention times on plasma membranes [37]. Aberrantly glycosylated RTKs often have increase plasma membrane retention times, causing cells to have sustained proliferative signalling and increased oncogenic activities. Glycan structures are also known to induce angiogenesis and increase development of vasculatures through signalling of RTKs [38].

Previously reported RON therapeutic antibodies target glycosylated RON protein [39], having used RON expressing cells as immunogens for antibody production. In recent years, there are have been more reports of aberrant glycosylation of tyrosine kinases including RON as an emerging hallmark of cancer [40]. N-glycosylations, in particular,
Glycosylation is one of the most abundant post-translational modification on proteins and more than $80 \%$ of human proteins are glycosylated [34]. RON tyrosine kinases are 
critically affect the structure of the extracellular domain of tyrosine kinases, leading to altered membrane interactions $[30,41]$. This altered structure and membrane interaction of the extracellular protein may potentially be a hindrance for therapeutic agents like monoclonal antibodies or drug candidates, as previously exposed epitopes in properly glycosylated antigens may be hidden in the altered conformations [42]. For our study, we unconventionally chose E. coli bacteria produced recombinant RON antigens (as described in Fig. 1b) as our immunogen. E. coli bacteria has limited capabilities for the production of glycoproteins, and most recombinant proteins produced are thought to be unglycosylated [43]. Expectedly, as seen in Fig. 4, our antibodies showed increased binding to cells treated with deglycosylation agent tunicamycin, further confirming that our antibodies bind to deglycosylated forms of RON.

\section{Wider therapeutic potential}

Previous studies on $\mathrm{RON}$ therapeutic antibodies reported a 30-50\% inhibition in tumour growth compared with control antibodies [44]. In our mouse xenograft studies, we observed an inhibition of up to $80 \%$ for $6 \mathrm{E} 6$. This was a surprising finding given that 6E6 did not display signs of antibody internalisation, inhibition of cell proliferation or migration in our in vitro assays and is only able to detect very low levels of RON antigen at the cell surface. A possible explanation is that immune cell recruitment is responsible for the superior anti-tumour effect observed. $6 \mathrm{E} 6$ is of mouse IgG2a isotype, while the other antibodies are of IgG1 isotype. The control mouse $\operatorname{IgG}$ used is a commercially available mouse IgG polyclonal antibody, containing a mixture of IgG isotypes. Mouse IgG2a antibodies are able to engage activatory $\mathrm{Fc} \gamma \mathrm{R}$ with higher affinities than other mouse antibody isotypes, leading to a more effective therapy [45]. In addition, 6E6 antibody targets both glycosylated and unglycosylated RON proteins, which potentially widens the different glycosylation forms of RON protein the antibody is able to bind to. Conventional antibodies that target only the glycosylated form of RON may likely overlook the more abundant aberrantly glycosylated proteins and fail to achieve sufficient therapeutic efficacies.

Glycosylation of onco-proteins plays a more important role in tumour development and progression than previously thought. Cancer cells often have increased expression or activities of glycotransferases and display aberrant glycophenotypes, differentiating them from their normal counterparts. Moving forward, new knowledge on cancer glycobiology will potentially revolutionize the way clinicians and scientist screen for specific glycan-based immunotherapies, as it is no longer possible to look past protein glycobiology in our drug designs for oncotargets [46].

\section{Complex antigenic structure of RON}

Our panel of antibodies begin to reveal a complex antigenicity for the RON protein. While the anti-alpha chain antibodies work well in western blots allowing precise epitope mapping of the highly active 6E6 antibody (Fig. 6) all of the antibodies to the beta chain fail to bind to RON in this format suggesting that the epitopes require some folding or modification of the RON protein. Considering that the immunogen was a GST protein produced in $E$. coli this is unusual. In the same vein the 6E6 antibody recognises an epitope that is far from a glycosylation site and yet in cell biology studies binding to 6E6 is enhanced by treatment with tunicamycin. Perhaps most provocative of all is that the most active antibody in xenografts is one that would not normally be selected for development since it has low cell surface binding and poor endocytosis. The resolution of these apparent enigmas should yield valuable insights into antibody therapies and the reagents described here will allow a detailed examination of RON expression and modification in human cancers. The detailed mapping of the 6E6 epitope will help us to appreciate the types of protein folding alteration that occur in cancer cells and that may differ when those cells are grown in tissue culture vs. in the microenvironment of an actively growing tumour. Our results strongly suggest that a key step in the development of such reagents will be the use of quantitative imaging methods to establish the level of epitope exposure in vivo and also have implications for protein antigenicity in general since the recognition of an epitope seen here in the small sulfhydryl peptide loop has also been seen in other tyrosine kinase receptors.

\section{Methods}

\section{Recombinant RON antigen design, expression and purification}

The amino acid sequence of RON was analysed for antigenicity with the Jameson-Wolf algorithm in Lasergene Protean v8.1 program (DNASTAR Inc., Madison, WI).

The entry vector containing full length human RON cDNA in pCMV6 vector (RC212786) was obtained from Origene. Three truncated regions of RON were selected based on the most antigenic sequences in the extracellular regions and subcloned into pGEX-4T1 vector (GE Healthcare) to create GST RON fusion protein expression vectors. The recombinant plasmids were transformed into BL21 $E$. coli competent cells (Invitrogen). Single colonies were picked for prokaryotic expression. Protein expression was induced by addition of IPTG (isopropyl- $\beta$-D-thio-galactoside). Cells were recovered by centrifugation at $6000 \mathrm{rpm}$ 
and resuspended in lysis buffer $(20 \mathrm{mM}$ Tris- $\mathrm{HCl}, \mathrm{pH} 8.0$, $1 \mathrm{M} \mathrm{NaCl}, 10 \%$ glycerol, $0.1 \%$ Triton $\mathrm{X}-100$ and $1 \mathrm{mM}$ DTT). Resuspended cells were lysed by sonication on ice using a sonicator (Sonics, Vibracell, USA). The resulting suspension was centrifuged at $18,000 \mathrm{rpm}$ for $40 \mathrm{~min}$ and the supernatant obtained was used for protein purification. The supernatant of the bacterial lysate was loaded on a glutathione column, washed with $20 \mathrm{mM}$ Tris- $\mathrm{HCl}, \mathrm{pH} 8.0$, $1 \mathrm{M} \mathrm{NaCl}, 10 \%$ glycerol, $0.1 \%$ Triton $\mathrm{X}-100$, and $1 \mathrm{mM}$ DTT. The GST-tagged RON protein was eluted using a buffer of $20 \mathrm{mM}$ Tris- $\mathrm{HCl}$, pH 9.6, $100 \mathrm{mM} \mathrm{NaCl}, 1 \mathrm{mM}$ DTT, and $10 \mathrm{mM}$ glutathione. The eluted protein fractions were collected for analysis by SDS-PAGE and dialysed into PBS before immunization.

\section{Immunization of truncated RON into mice}

Five 8-week-old Balb/c female mice were obtained from Biological Resource Center (Singapore) and inoculated with recombinant human protein RON immunogens. The first immunisation was performed intraperitoneally with Sigma Adjuvant System (Sigma) as adjuvant, followed by five intraperitoneal and subcutaneous injections at 3 weeks interval in the same adjuvant. One week after the fourth immunization, blood was drawn from each mouse via cheek bleed using a lancet (MEDIpoint International Inc.). Approximately $10 \mu \mathrm{l}$ of blood was centrifuged for $10 \mathrm{~min}$ at $1600 \mathrm{rpm}$ and serum was aspirated and stored at $4{ }^{\circ} \mathrm{C}$. Subsequently the antibody response was measured by enzyme-linked immunosorbent assay (ELISA) with the RON protein used for immunisation immobilized on the ELISA plate. The mouse with the highest serum antibody titre was selected as the spleen donor for fusion with myeloma cell line SP2/0.

\section{Fusion of mice spleen with myeloma cells to obtain hybridoma cells}

The mice received a final boost by intravenous injection of the RON fusion protein without adjuvant. Mouse myeloma $\mathrm{SP} 2 / 0$ cell line was used as the fusion partner. Thus, 1 week before fusion, cells were cultured in RPMI (Gibco) and 10\% FBS until they attained $>70 \%$ confluency in the logarithmic phase. The spleen cells of the immunised mouse were removed under sterile conditions. Generation, selection and cloning of hybridoma cells were performed using the ClonaCell-HY Hybridoma Cloning kit (STEMCELL Technologies) following the manufacturer's protocol.

\section{Screening of hybridoma cells for RON antibodies ELISA}

Hybridoma clones secreting mAbs targeting human RON were selected by ELISA assay with the use of 96-well
Maxisorp plates (Nunc) coated separately with recombinant RON and GST at $1 \mu \mathrm{g} / \mathrm{ml}$. Supernatant collected from individual hybridoma wells were tested on ELISA plates. $10 \%$ foetal bovine serum (FBS) was used for blocking and antibody dilution. 1XPBS with $0.05 \%$ Tween 20 (PBST) was used for washes. After washing, bound IgGs were detected using 1:5000 goat anti-mouse $\operatorname{IgG}$ conjugated to HRP (Biorad) in PBST with 10\% FBS. After washing, the plates were developed with $1 \mathrm{X}$ TMB ELISA substrate solution (Sigma). Absorbance was measured at $650 \mathrm{~nm}$ with EnVision Plate Reader (Perkin Elmer).

\section{Immunofluorescence staining}

The $4 \%$ paraformaldehyde fixed transfected cells were subjected to permeabilization with $0.4 \%$ Triton X-100 for 20 min. After rinsing with PBS, cells were blocked with 5\% BSA in PBSTritonX (PBSTX) for $20 \mathrm{~min}$, followed by overnight incubation in hybridoma supernatant at $4{ }^{\circ} \mathrm{C}$. IgGs were detected using 1:1000 goat Alexa Fluor 488 Donkey anti-mouse IgG conjugated (Life Technologies) in PBSTX with $1 \%$ BSA. Subsequently, cells were counterstained with DAPI, and viewed with the Incell Analyzer (GE Healthcare).

\section{Immunohistochemical staining of paraffin- embedded sections}

Tumour tissues from the HT29 xenograft mouse model were processed into paraffin blocks by the Advanced Molecular Pathology Laboratory (AMPL), Institute of Molecular and Cell Biology. Wax sections at $5 \mu \mathrm{m}$ were then collected onto slides (Leica Biosystems) and dried at $50{ }^{\circ} \mathrm{C}$ hot plate for $1 \mathrm{~h}$.

Sections were deparaffinized in xylene (ChemTech Trading) and rehydrated through descending percentages of ethanol (ChemTech Trading). Tissue sections were heated with Target Retrieval Solution, pH6 (Dako) in the 2100 Antigen Retriever (Aptum Biologics). Endogenous peroxidase was blocked with $2 \%(\mathrm{v} / \mathrm{v})$ hydrogen peroxide (Merck) in PBS for $30 \mathrm{~min}$, rinsed with water then PBS. Sections were blocked with $10 \%$ (v/v) goat serum (Dako) in PBS for $1 \mathrm{~h}$ then incubated with primary antibodies at $4{ }^{\circ} \mathrm{C}$ overnight.

Sections were washed in running tap water before being incubated with EnVision peroxidase labelled polymer conjugated to goat anti-mouse or anti-rabbit immunoglobulins (Dako; neat concentrations). Antigen-antibody interaction was then visualized using 3,3'-diaminobenzidine as a substrate, and the sections were lightly counterstained with hematoxylin before dehydrating and mounting in Cytoseal 60 synthetic resin (Richard-Allan Scientific ${ }^{\mathrm{TM}}$, Fisher Scientific). Slides were imaged under bright field using the 
AxioImager (Zeiss) light microscope and analysed with AxioVision Rel 4.8 software (Carl Zeiss AG).

\section{Flow cytometry}

In total, $1 \times 10^{6}$ RAJI cells (ATCC) were harvested and washed in PBS. The cells were blocked in 1\% BSA/PBS. Cells were subjected to different fixation methods (unfixed, fixed in 4\% PFA or fixed in acetone methanol) before incubation with $1 \mu \mathrm{g} / \mathrm{ml}$ RON antibodies. Fixation procedures were carried out for $20 \mathrm{~min}$. Cells were incubated with goat anti-mouse IgG FITC-conjugated secondary antibodies (Invitrogen) and resuspended in PBS. FACS analysis was performed using Becton Dickinson FACS LSRII Machine and FlowJo (Tree Star Inc., USA) software was used for data analysis.

\section{Antibody inhibition of cell proliferation assay}

RON expressing HT29 cells (ATCC) were transferred to a 96-well plate and imaged using the IncuCyte HD system (Essen BioScience). Frames were captured at $2 \mathrm{~h}$ intervals from four separate $950 \times 760 \mu \mathrm{m}^{2}$ regions per well using a $\times 20$ objective. Seeded cells were serum starved for $16 \mathrm{~h}$ and filter-sterilized purified $\mathrm{mAb}$ were added into each treatment wells. Antibodies were added to the wells and experimental wells were run in triplicates. Cell confluency data were calculated by the IncuCyte software. Values from all three regions of each well were pooled and averaged across all three replicates.

\section{Wound healing assays}

RON expressing HT29 cells were transferred to a 96-well plate and scratch wound was created using the IncuCyte Wound Maker (Essen BioScience). Seeded cells were serum starved for $16 \mathrm{~h}$ and filter-sterilized purified antibodies were added into each treatment wells. Antibodies were added to the wells and experimental wells were run in triplicates. Images were obtained using the IncuCyte HD system (Essen BioScience) Frames were captured at $2 \mathrm{~h}$ intervals from four separate $950 \times 760 \mu^{2}$ regions per well using a $\times 20$ objective. Data images and confluency data were processed using Image $\mathbf{J}$ software. Values from all three regions of each well were pooled and averaged across all three replicates.

\section{Western blot assays}

Lysis was performed using RIPA buffer (Thermo Scientific) supplemented with protease inhibitor cocktail (Roche). The QuickStart Bradford protein assay (BioRad) was used to determine protein concentration with BSA as standard.
Equal amounts of total protein were mixed with NuPAGE lithium dodecyl sulphate (LDS) and sample reducing buffer (Thermo Scientific), heated for $5 \mathrm{~min}$ at $95^{\circ} \mathrm{C}$ and loaded into NuPAGE $10 \%$ or $12 \%$ Bis-Tris gels (Life Technologies) for electrophoresis. Separated proteins were transferred onto nitrocellulose membranes using the iBlot 2 gel transfer device (Thermo Scientific). Blocking was performed with $5 \%$ milk or bovine serum albumin (BSA) in tris-buffered saline supplemented with $0.1 \%$ tween (TBST). ERK1/2 (4348S) and p-ERK (8544S) antibodies were from Cell Signaling Technology. RON antibody was made inhouse and Actin-HRP (A3854) was from Sigma-Aldrich. Anti-rabbit (P0217) and anti-mouse (P0161) secondary antibodies were from Dako. The enhanced chemiluminescence (ECL) reagent used was SuperSignal West Dura Extended Duration Substrate (Thermo Scientific, \#34076). Imaging and acquisition was performed with Licor Odyssey Fc and Image Studio (version 3.1).

\section{Human xenograft mouse model}

For HT-29 cancer cell xenograft experiments, female $n u / n u$ nude mice (ages 8 weeks; Biological Resource Centre) were inoculated subcutaneously with $5 \times 10^{6}$ HT29-luc2 cells (Perkin Elmer) per mouse. Mice were randomized into different groups (5 mice per group). The study was performed by treating mice with antibodies at $25 \mathrm{mg} / \mathrm{kg}$ every 3-4 days for a total of 8 intravenous injections. Experiment was performed blinded. Bioluminescence from individual tumours was measured every 7 days using Caliper IVIS image system (Perkin Elmer). Animals were euthanized when tumour volumes exceeded $2000 \mathrm{~mm}^{3}$ or if tumours became necrotic or ulcerated through the skin. Tumour sizes were also measured using digital calipers. At the end of the experiment, the mice were sacrificed and tumours were collected and weighed on a digital weighing scale. The tumour tissues were fixed in $10 \%$ non-buffered formalin before embedding in paraffin blocks for histology analysis. All animals were housed and experiments were carried out in Biological Resource Center (Singapore) animal facility. The IACUC (Institutional Animal Care and Use Committee) of A*STAR Biological Resource Center (Singapore) approved all animal protocols used in this study under protocol 116147.

\section{Simulation details}

The atomic coordinates of the extracellular domain of Ron crystal structure (PDB ID: 4FWW) was downloaded from protein data bank (PDB). The terminal ends of the protein were capped with ACE and NME functional groups, respectively. All known disulphide bonds in the structure were established using the bond command in TLEAP. The 
structure was solvated in a cuboid box ensuring a minimum distance of $10 \AA$ between the structure and the box boundary. The PMEMD module of AMBER 14 [47] was used to carry out molecular dynamic simulation with a time step of $2 \mathrm{fs}$. The system was first subjected to energy minimizations (using steepest descent and conjugate gradient algorithms) and then heated to $300 \mathrm{~K}$. It was equilibrated for $500 \mathrm{ps}$ and subjected to $200 \mathrm{~ns}$ of production dynamics in the NPT ensemble. The regulation of simulation temperature $(300 \mathrm{~K})$ and pressure $(1 \mathrm{~atm})$, treatment of electrostatic interactions and constrain for bonds involving hydrogen atoms were implemented as previously described by Lama et al. [48].

Acknowledgements We would like to acknowledge Dr. Farid Ghadessy, Dr. Zhaoru Lin and Dr. Khian Hong Pua in their critical reading and editing of the paper.

Funding This work was supported by A*STAR.

\section{Compliance with ethical standards}

Conflict of interest The authors declare that they have no conflict of interest.

Publisher's note: Springer Nature remains neutral with regard to jurisdictional claims in published maps and institutional affiliations.

Open Access This article is licensed under a Creative Commons Attribution 4.0 International License, which permits use, sharing, adaptation, distribution and reproduction in any medium or format, as long as you give appropriate credit to the original author(s) and the source, provide a link to the Creative Commons license, and indicate if changes were made. The images or other third party material in this article are included in the article's Creative Commons license, unless indicated otherwise in a credit line to the material. If material is not included in the article's Creative Commons license and your intended use is not permitted by statutory regulation or exceeds the permitted use, you will need to obtain permission directly from the copyright holder. To view a copy of this license, visit http://creativecommons. org/licenses/by/4.0/.

\section{References}

1. Wang M-H, Lee W, Luo Y-L, Weis M, Yao H-P. Altered expression of the RON receptor tyrosine kinase in various epithelial cancers and its contribution to tumourigenic phenotypes in thyroid cancer cells. J Pathol. 2007;213:402-11.

2. Morrison AC, Wilson CB, Ray M, Correll PH. Macrophagestimulating protein, the ligand for the stem cell-derived tyrosine kinase/RON receptor tyrosine kinase, inhibits IL-12 production by primary peritoneal macrophages stimulated with IFN-gamma and lipopolysaccharide. J Immunol. 2004;172:1825-32.

3. Wagh PK, Peace BE, Waltz SE. Met-related receptor tyrosine kinase Ron in tumor growth and metastasis. Adv cancer Res. 2008;100:1-33.

4. Angeloni D, Danilkovitch-Miagkova A, Miagkov A, Leonard EJ, Lerman MI. The soluble sema domain of the RON receptor inhibits macrophage-stimulating protein-induced receptor activation. J Biol Chem. 2004;279:3726-32.
5. Ronsin C, Muscatelli F, Mattei MG, Breathnach R. A novel putative receptor protein tyrosine kinase of the met family. Oncogene. 1993;8:1195-202.

6. Krishnaswamy S, Mohammed AK, Tripathi G, Alokail MS, AlDaghri NM. Splice variants of the extracellular region of RON receptor tyrosine kinase in lung cancer cell lines identified by PCR and sequencing. BMC Cancer. 2017;17:738.

7. Ling Y, Kuang Y, Chen L-L, Lao W-F, Zhu Y-R, Wang L-Q, et al. A novel RON splice variant lacking exon 2 activates the PI3K/AKT pathway via PTEN phosphorylation in colorectal carcinoma cells. Oncotarget. 2017;8:39101-16.

8. Zhang K, Zhou YQ, Yao HP, Wang MH. Alterations in a defined extracellular region of the RON receptor tyrosine kinase promote RON-mediated motile and invasive phenotypes in epithelial cells. Int J Oncol. 2010;36:255-64.

9. Kang JG, Ko JH, Kim YS. Pros and cons of using aberrant glycosylation as companion biomarkers for therapeutics in cancer. BMB Rep. 2011;44:765-71.

10. Yao HP, Zhou YQ, Zhang R, Wang MH. MSP-RON signalling in cancer: pathogenesis and therapeutic potential. Nat Rev Cancer. 2013;13:466-81.

11. Meyer SE, Zinser GM, Stuart WD, Pathrose P, Waltz SE. The Ron receptor tyrosine kinase negatively regulates mammary gland branching morphogenesis. Dev Biol. 2009;333:173-85.

12. Andrade K, Fornetti J, Zhao L, Miller SC, Randall RL, Anderson N, et al. RON kinase: A target for treatment of cancer-induced bone destruction and osteoporosis. Sci Transl Med. 2017;9:eaai9338.

13. Chen J-F, Yu B-X, Yu R, Ma L, Lv X-Y, Cheng Y, et al. Monoclonal antibody $\mathrm{Zt} / \mathrm{g} 4$ targeting RON receptor tyrosine kinase enhances chemosensitivity of bladder cancer cells to Epirubicin by promoting G1/S arrest and apoptosis. Oncol Rep. 2017;37:721-8.

14. Dussault I, Bellon SF. From concept to reality: the long road to cMet and RON receptor tyrosine kinase inhibitors for the treatment of cancer. Anti-cancer Agent Med Chem. 2009;9:221-9.

15. Zou Y, Howell GM, Humphrey LE, Wang J, Brattain MG. Ron knockdown and Ron monoclonal antibody IMC-RON8 sensitize pancreatic cancer to histone deacetylase inhibitors (HDACi). PLOS ONE. 2013;8:e69992.

16. Chang K, Karnad A, Zhao S, Freeman JW. Roles of c-Met and RON kinases in tumor progression and their potential as therapeutic targets. Oncotarget. 2015;6:3507-18.

17. Wang M-H, Zhang R, Zhou Y-Q, Yao H-P. Pathogenesis of RON receptor tyrosine kinase in cancer cells: activation mechanism, functional crosstalk, and signaling addiction. J Biomed Res. 2013;27:345-56.

18. LoRusso PM, Gounder M, Jalal SI, Andre V, Kambhampati SRP, Loizos N, et al. Phase 1 study of narnatumab, an anti-RON receptor monoclonal antibody, in patients with advanced solid tumors. Investig New Drugs. 2017;35:442-50.

19. Chakedis J, French R, Babicky M, Jaquish D, Mose E, Cheng P, et al. Characterization of RON protein isoforms in pancreatic cancer: implications for biology and therapeutics. Oncotarget. 2016;7:45959-75.

20. Greenbaum A, Rajput A, Wan G. RON kinase isoforms demonstrate variable cell motility in normal cells. Heliyon. 2016;2:e0153.

21. Hanahan D, Weinberg Robert A. Hallmarks of cancer: the next generation. Cell. 2011;144:646-74.

22. Ellis CR, Maiti B, Noid WG. Specific and nonspecific effects of glycosylation. J Am Chem Soc. 2012;134:8184-93.

23. Wong C-H. Protein glycosylation: new challenges and opportunities. J Org Chem. 2005;70:4219-25.

24. Haynes PA. Phosphoglycosylation: a new structural class of glycosylation? Glycobiology. 1998;8:1-5.

25. Ferreira IG, Pucci M, Venturi G, Malagolini N, Chiricolo M, Dall'Olio F. Glycosylation as a main regulator of growth and death factor receptors signaling. Int J Mol Sci. 2018;19:580. 
26. Lam PV, Goldman R, Karagiannis K, Narsule T, Simonyan V, Soika V, et al. Structure-based comparative analysis and prediction of N-linked glycosylation sites in evolutionarily distant eukaryotes. Genom, Proteom Bioinforma. 2013;11:96-104.

27. Benham AM. Protein secretion and the endoplasmic reticulum. CSH Perspect Biol. 2012;4:a012872.

28. Sarabipour S, Hristova K. FGFR3 transmembrane domain interactions persist in the presence of its extracellular domain. Biophys J. 2013;105:165-71.

29. de-Freitas-Junior JCM, Andrade-da-Costa J, Silva MC, Pinho SS. Glycans as regulatory elements of the insulin/IGF system: impact in cancer progression. Int J Mol Sci. 2017;18:1921.

30. Mereiter S, Magalhaes A, Adamczyk B, Jin C, Almeida A, Drici L, et al. Glycomic analysis of gastric carcinoma cells discloses glycans as modulators of RON receptor tyrosine kinase activation in cancer. Biochim et Biophys acta. 2016;1860:1795-808.

31. Johns TG, Adams TE, Cochran JR, Hall NE, Hoyne PA, Olsen $\mathrm{MJ}$, et al. Identification of the epitope for the epidermal growth factor receptor-specific monoclonal antibody 806 reveals that it preferentially recognizes an untethered form of the receptor. J Biol Chem. 2004;279:30375-84.

32. Catenacci DV, Cervantes G, Yala S, Nelson EA, El-Hashani E, Kanteti R, et al. RON (MST1R) is a novel prognostic marker and therapeutic target for gastroesophageal adenocarcinoma. Cancer Biol Ther. 2011;12:9-46.

33. Wong JS, Warbrick E, Vojtesek B, Hill J, Lane DP. Anti-c-Met antibodies recognising a temperature sensitive epitope, inhibit cell growth. Oncotarget. 2013;4:1019-36.

34. Very N, Lefebvre T, El Yazidi-Belkoura I. Drug resistance related to aberrant glycosylation in colorectal cancer. Oncotarget. 2018;9:1380-402.

35. Chao KL, Tsai IW, Chen C, Herzberg O. Crystal structure of the Sema-PSI extracellular domain of human RON receptor tyrosine kinase. PLOS ONE. 2012;7:e41912.

36. Gorlatova N, Chao K, Pal LR, Araj RH, Galkin A, Turko I, et al. Protein characterization of a candidate mechanism SNP for Crohn's disease: the macrophage stimulating protein R689C substitution. PLOS One. 2011;6:e27269.
37. Itkonen HM, Mills IG. Studying N-linked glycosylation of receptor tyrosine kinases. Methods Mol Biol (Clifton, NJ). 2015;1233:103-9.

38. Munkley J, Elliott DJ. Hallmarks of glycosylation in cancer. Oncotarget. 2016;7:35478-89.

39. Yao HP, Luo YL, Feng L, Cheng LF, Lu Y, Li W, et al. Agonistic monoclonal antibodies potentiate tumorigenic and invasive activities of splicing variant of the RON receptor tyrosine kinase. Cancer Biol Ther. 2006;5:1179-86.

40. Kaszuba K, Grzybek M, Orłowski A, Danne R, Róg T, Simons K, et al. N-Glycosylation as determinant of epidermal growth factor receptor conformation in membranes. Proc Natl Acad Sci USA. 2015;112:4334-9.

41. Gomes C, Osório H, Pinto MT, Campos D, Oliveira MJ, Reis CA. Expression of ST3GAL4 leads to SLex expression and induces cMet activation and an invasive phenotype in gastric carcinoma cells. PLOS ONE. 2013;8:e66737.

42. Cazet A, Julien S, Bobowski M, Burchell J, Delannoy P. Tumourassociated carbohydrate antigens in breast cancer. Breast Cancer Res. 2010;12:204.

43. Benz I, Schmidt MA. Never say never again: protein glycosylation in pathogenic bacteria. Mol Microbiol. 2002;45:267-76.

44. Yao H-P, Zhou Y-Q, Ma Q, Guin S, Padhye SS, Zhang R-W, et al. The monoclonal antibody $\mathrm{Zt} / \mathrm{f} 2$ targeting $\mathrm{RON}$ receptor tyrosine kinase as potential therapeutics against tumor growthmediated by colon cancer cells. Mol Cancer. 2011;10:82.

45. Beers SA, Glennie MJ, White AL. Influence of immunoglobulin isotype on therapeutic antibody function. Blood. 2016;127:1097-101.

46. Ho W-L, Hsu W-M, Huang M-C, Kadomatsu K, Nakagawara A. Protein glycosylation in cancers and its potential therapeutic applications in neuroblastoma. J Hematol Oncol. 2016;9:100.

47. Case VB DA, Berryman JT, Betz RM, Cai Q, Cerutti DS, Cheatham TE 3rd, et al. AMBER 14. San Francisco: University of California; 2014.

48. Lama D, Quah ST, Verma CS, Lakshminarayanan R, Beuerman RW, Lane DP, et al. Rational optimization of conformational effects induced by hydrocarbon staples in peptides and their binding interfaces. Sci Rep. 2013;3:3451. 